Journal of Engineering and Applied Sciences 15 (6): 1322-1329, 2020

ISSN: 1816-949X

(C) Medwell Journals, 2020

\title{
Analysis and Diagnostic of Colombian Automated Manufacturing Production
}

\author{
Kevin Steve Mariño Salas \\ Facultad Tecnológica, Universidad Distrital Francisco José de Caldas, Bogotá D.C., Colombia
}

\begin{abstract}
The study presents an approach to automation with regards to manufacturing processes in the Colombian industrial context taking into account different sources of information that generate a multiplicity of data concerning the present and future of companies facing innovation and national and international competitivity. On the other hand, the benefits of automation implementation in the manufacturing industry are exposed from several angles, thus, easing up the understanding of its implementation. In addition to that, a comparative analysis is carried out with respect to the manufacturing processes implemented in Colombia and current industry trends and feasible suggestions for their application to manufacturing procedures, so as to improve Colombian economy are proposed.
\end{abstract}

Key words: Automation, manufacture, industry 4.0, production, innovation, implementation

\section{INTRODUCTION}

Electronic engineering has stood throughout the last decades, its progress speeds up industrial development and strengthens modern science. Industrial automation is a branch of electronic engineering that applies technology to industrial automatic control, control systems and data supervision, industrial instruments, process control and industrial communication networks (Trappey et al., 2016). Automation, that is to say the automatic and coordinated execution of necessary processes to their utmost degree of perfection has been an ever changing process and processes have evolved on the basis of previously obtained results. This being the case, a revolution has been made that consists the permanent interconnection among machines and workers as far as information transfer and process details. Industry 4.0 allows to be immediately aware of what is going on with in the factory, obtaining detailed results for decision-making with respect to the same. Massive automation and robotization, together with new technology represent a very beneficial opportunity for the sector in upcoming years. The impact of this revolution is going to be seen indifferent industries, since, it will transform the services a company offers and will give birth to new production structures.

Advanced manufacturing is explained by the co-evolution and confluence between operation technologies, associated to industrial process automation and new IT platforms such as the internet of things, new generation networks, cloud computing, big data analytics and artificial intelligence system (Morrish et al., 2016). Therefore, it is defined as the activity that leads production and digital technology use, so as to dominate the industrial sector.
The formation of these tools will allow to change the course of all production systems through modernization, smart factory building, that is to say factories where every process is automated, that imply beneficial results, like: cost reduction for the company: better times and cost reduction that will result in a general improvement for general economy. Considering the positioning of Colombia at the global level, we observe the disadvantage with respect to factory 4.0 implementation as far as manufacturing production goes, so, Colombia must elaborate and conduct research on technology proposals, taking industry future and technology into consideration.

\section{MATERIALS AND METHODS}

This research was organized in three phases: in the initial phase a study about the state of the manufacturing industry in Colombia, the industrial context, the positioning of Colombia at a global level was carried out. Several real research criteria were used and provided the figures needed to be able to make an accurate comparison, observing the negative and positive points identifying the failures that the Colombian industry has in terms of automated technological processes. In this case, it was identified that the industrial companies which do not have manufacturing automation have lower productivity indicators when compared to industrial companies than if you count on it. We know that an integral part of the factory of the future is the extension and expansion of supply and supply chains, breaking all the basic and traditional schemes to create a single installation among clients, suppliers, industry and academic world. A brief comparison of current and 4.0 industry is available in Table 1 (Qin et al., 2016). 
J. Eng. Applied Sci., 15 (6): 1322-1329, 2020

Table 1: Comparison between factory that implements common standards and a factory of the 4.0 industry (Qin et al., 2016)

\begin{tabular}{lllll}
\hline Data source & Today's factory & & Industry 4.0 & \\
& Attributes & Technologies & Attributes & Technologies \\
\hline $\begin{array}{l}\text { Component } \\
\text { Sensor }\end{array}$ & Precision & Smart sensors and fault detection & Self-conscious & $\begin{array}{l}\text { Monitoring of degradation and prediction } \\
\text { of remaining useful life }\end{array}$ \\
$\begin{array}{l}\text { Machine } \\
\text { Controller }\end{array}$ & $\begin{array}{l}\text { Productivity and } \\
\text { performance }\end{array}$ & $\begin{array}{l}\text { Monitoring and diagnosis based } \\
\text { on the condition }\end{array}$ & $\begin{array}{l}\text { Self-conscious } \\
\text { Self-predict } \\
\text { Self-compare }\end{array}$ & $\begin{array}{l}\text { Time of activity with predictive monitoring } \\
\text { of health }\end{array}$ \\
$\begin{array}{l}\text { Network system } \\
\text { Productivity and OEE }\end{array}$ & $\begin{array}{l}\text { Lean operations: work and } \\
\text { waste reduction }\end{array}$ & $\begin{array}{l}\text { Auto configuration } \\
\text { Self-maintenance } \\
\text { Self-organized }\end{array}$ & Productivity without worries \\
\hline
\end{tabular}

In the second phase, the main world powers are taken as reference. The kind of advanced manufacturing that each of the companies provide to the economy of their country, generating benefits that are reflected in the strengthening of infrastructures, new technologies, economic indicators and low worker activity, since, they have virtual machines that take care of mechanical and routine work movements. In addition to that, the positioning of the leading countries and the competitiveness of the companies concerning innovation and indicators for said operations. According to Deloitte's Global Manufacturing Competitiveness index, in 2010, 2013 and 2016 China was the most competitive country in manufacturing, while the United States was improving its competitiveness index. By 2020, the United States is projected to take the lead in competitiveness, followed by China in the second position and Germany in the third. (Qin et al., 2016).

Finally, a series of suggestions and recommendations are made regarding the improvement policies and trends associated with the Colombian manufacturing industry, generating key points for the optimization of its resources and the implementation of new technologies. All this, in order to achieve innovation in their production processes and the opportunity to enter into competition with large companies that have advanced manufacturing at a global level (ICE., 2015).

\section{RESULTS AND DISCUSSION}

The main parameter to achieve the leadership of the Colombian industry is based on the new technological industries. In 1950, the leading role was exercised by the steel, machines and tools industry. Then, in 1970 the semiconductor, electronics and hardware industry took the leading role and subsequently, internet in the 1990s. Nowadays, the leading role will be taken by manufacturing based on digital platforms, robots and artificial intelligence, however, talking about the structural crisis of Colombian manufacturing is a key problem. Media show us that our industrial base is weak as far as productivity, innovation and is far from
Table 2: Real production of the manufacturing industry broken down by regions

Annual change (\%) III quarter, 2018

\begin{tabular}{lc} 
Region & Percentage \\
\hline Barranquilla & 12 \\
Bogotá & -0.2 \\
Cali & 2.4 \\
Eje Cafetero & 0.3 \\
Medellín & 0.2 \\
Santander & 2.1 \\
National total & 3.5 \\
\hline
\end{tabular}

competing with world powers. It is clear that Colombia needs to reduce its "country cost", an indicator in international trade as an appraisal factor of a country's competitiveness, since, it involves all costs or tax input that unnecessarily affects and increases the cost of products, both in internal and external markets. Infrastructure, transportation, bureaucratic procedures and others should be reduced to overcome barriers and compete worldwide, thus, being looked upon for such operations (ICE., 2015).

It was identified that industries in Colombia have an insufficient degree of technological innovation which shows a productive processes delay that, on its turn, generates a productivity deficit and a low earnings rate. Taking this into account, the importance of a formal innovation structure lies in that it defines the way in which employees interact, facilitates decision-making and avoids experimentation without prior control and feedback, thus, allowing innovation capacity to be oriented towards business goals. Manufacturing models must evolve from specialized automation processes at the factory level and isolated and standardized robotization, to more complex processes encompassing the whole product value chain (Panfilenko et al., 2016). Leading countries are supporting the main industrial conglomerates in developing new technological platform oriented to enhance industrial competitiveness (Smit et al., 2016) (Table 2).

The statistical report describing the real production of the manufacturing industry according to the annual 
J. Eng. Applied Sci., 15 (6): 1322-1329, 2020

Table 3: Real production of the manufacturing industry in Bogota

\begin{tabular}{|c|c|c|c|c|c|c|c|c|c|c|c|c|c|c|c|c|c|}
\hline \multirow[b]{2}{*}{ Region } & \multicolumn{2}{|c|}{2014} & \multicolumn{4}{|l|}{2015} & \multicolumn{4}{|c|}{2016} & \multicolumn{4}{|l|}{2017} & \multicolumn{3}{|l|}{2018} \\
\hline & lll & IV & 1 & ll & 111 & lV & 1 & $\mathrm{Ll}$ & lll & lV & 1 & ll & lll & lV & l & ll & lll \\
\hline National T. & & & $-0,2$ & 0,7 & 2,7 & 4,7 & 4,8 & 7,0 & & 1,9 & 1,1 & $-2,9$ & 0,3 & $-0,5$ & 0,1 & 4,9 & 3,5 \\
\hline Barranquilla & 1,1 & 3,3 & 3,6 & 1,6 & 4,2 & 3,6 & 6,3 & 5,5 & 6,4 & 3,1 & 1,9 & $-1,0$ & $.5,2$ & 1,5 & 4,1 & 7,4 & 12,0 \\
\hline Bogotá & $-2,3$ & 1,8 & $-1,8$ & $-0,4$ & $-0,9$ & 0,7 & 2,3 & 3,4 & $-0,3$ & $-2,8$ & $-4,1$ & $-9,2$ & $-3,8$ & $-4,5$ & $-3,2$ & 4,0 & $-0,2$ \\
\hline Cali & $-1,0$ & 1,8 & 5,2 & 4,0 & 2,4 & 2,7 & 0,8 & $-2,2$ & $-1,6$ & $-1,7$ & $-4,7$ & $-2,4$ & 0,1 & 1,0 & 0,5 & 4,3 & 2,4 \\
\hline Eje Cafetero & 3,1 & $-2,4$ & 5,4 & 7,8 & 6,5 & 6,9 & 5,5 & 3,5 & $-7,4$ & 0,2 & 2,0 & $-1,2$ & 11,9 & 0,0 & $-4,7$ & 3,3 & $-0,3$ \\
\hline Medellín & 8,4 & 2,9 & 1,5 & 1,1 & 3,3 & 4,4 & 2,3 & 4,6 & $-2,0$ & $-0,8$ & $-1,8$ & $-11,1$ & $-4,8$ & $-5,5$ & $-4,5$ & 7,4 & 0,2 \\
\hline Santander & 6,5 & 1,7 & 0,5 & $-2,6$ & 1,5 & 4,0 & 3,2 & 3,4 & $-5,3$ & $-8,0$ & $-5,7$ & $-3,6$ & $-2,6$ & $-4,2$ & 1,8 & 2,4 & 2,1 \\
\hline
\end{tabular}

variation \% and broken down by regions (lll quarter 2018), elaborated by the economic development observatory is summarized in the following table:

General ratios represent a low percentage of the manufacturing production (Table 2) considering that the main cities of Colombia should register higher indexes. In this phase, it can be identified that companies start considering technological innovation and since, their primary focus is to generate positive production rates and compete internationally, they must make production improvements which are specifically, defined as automation.

The city of Bogota being the capital of Colombia is the one with the most variations throughout the different periods of study. At the end of 2018, Bogota had a negative index and taking into account that the last quarter of the year is of the most productive from an industrial stand point, this should be reflected due to the great demand levels the country has in said season (Table 3). According to the figures the Q3 2018 manufacturing sample (MTRM) and real sales index decreased by $0.2 \%$, respectively. Among the sectors that recorded negative production trends in same quarter of the previous year we can find the notable mentions of the petroleum derivatives, basic chemical substances, tanning, shoes, bakery products industries.

The adoption of robotic process automation would provide us with a savings factor of more than $50 \%$ in industrial production processes with respect to routine tasks speed, precision and traceability (Zimmermann et al., 2017) and considering that the full implementation of the industry 4.0 is not going to happen soon and more, so with the low indicators of industrial growth in the country which is that we must strengthen these processes, since, industry represents a very important factor in gross domestic product.

South Korea, Germany, China, United Kingdom are the four countries that lead scientific automated production applied to rotating machines, cloud platforms; they implemented an intelligent real-time injection model. The use of factory 4.0 to carry out quality control and algorithm application for Cost Per Sale (CPS) implementation allows evaluating supply chain performance in real time (Baena et al., 2017). This information confirms the high efficiency, competitiveness and levels of automation, simulation, platforms, robotics and flexible manufacturing systems in these countries which allows them to have one of the best economies worldwide through excellent management in the supply chains (Baena et al., 2017).

Analysis and recommendations for Colombia: One of the improvement strategies that industrial companies can establish is updating their production models by automating them, in order to receive benefits in both innovation and financial aspects, taking into account that by automating manufacturing production, some guidelines such as improvement of quality standards, reduction of production losses, increase in repetitiveness and stability of manufacturing processes, reduction of physical and repetitive work, obtaining greater continuity of production on holidays, improvement of the relationship cost-benefit, the predominance of open vision to size the need and selection of the most viable technical and economic offer in terms of automation technology, given that, companies would have a valuable economic growth and generate a better position compared to their competencies obtaining favorable results.

Now, from the point of view of the structure of the manufacturing process, automation covers the qualitative and quantitative aspects of the technological process. In the qualitative part of the technological process, there are issues such as the type of process to be used (level of science and technology incorporated), the structure of the process flow and technological operations, the choice and adoption of the required technology (equipment, instruments, supplies, communication ...) (Kolberg and Zuhlke, 2015) Table 4 shows the main companies of advanced manufacturing where their priority is there search and development of the worker, training and continuous updating of the technology is a priority that each sector takes to have positive economic indicators, in order to enter the global competitiveness.

Through the generation of skills and knowledge based on new technologies, we realize that the automotive industry is in the first place, thanks to the incorporation of electronics, software and connectivity in automobiles. The industry continues to develop innovation far the development of electric, digital and autonomous vehicles. 
Table 4: Main advanced manufacturing companies (Rubmann et al., 2015)

\begin{tabular}{ll}
\hline Macro sectors & Main companies \\
\hline $\begin{array}{l}\text { Automotive industry } \\
\text { Auto parts and automotive equipment }\end{array}$ & $\begin{array}{l}\text { Toyota, Volkswagen, GM. Ford, Fiat Chrysler, Saic Motor, Daimler, Honda y Nissan } \\
\text { Robert Bosch, Denso, China South, Continental, ZF Friedrichshafen, Magna, Hyundai, Aisin, Johnson } \\
\text { Controls } \\
\text { Electrical equipment and components } \\
\text { Siemens, General Electric, Hitachi, ABB, United Technologies, Schneider Electric, Mitsubishi, Honeywell, } \\
\text { Toshiba, Daikin Industries }\end{array}$ \\
& $\begin{array}{l}\text { Samsung, LG, China Electronic, Boe Technology, Au Optronics, Innolux, Japan Display , Sharp, Byd Co } \\
\text { y Delta Electronics } \\
\text { Cachines and tools }\end{array}$ \\
Construction machinery & $\begin{array}{l}\text { Construcción y Minería Caterpillar, Deere, China National Machinery, Hitachi, Komatsu, Fiat, CNH, Atlas } \\
\text { Copco, Kubota y Shaanxi }\end{array}$ \\
Apple, Samsung, HP, Legend Holdings, Lenovo, Cisco, Panasonic, Sony, LG y Huawei
\end{tabular}

Table 5: Main advanced service companies (Thoben et al., 2017)

\begin{tabular}{ll}
\hline Macro sectors & Main companies \\
\hline Application software & Microsoft, SAP, Alphabet Inc., Tencent, Sony, Salesforce, Activision Blizzard, Adobe Systems, Intuit y \\
Data processing & Huawei, IBM, Accenture, Hewlett Packard, Fujitsu, Nec corp, Tata y NTT Data \\
Computer software & Microsoft, Oracle, IBM, Amazon, Vmware, Symantec, ATEA, CA Technologies, Citrix Systems y Itochu \\
& Techno-Solutions \\
Mobile telecommunications & Softbank Group, Vodafone, Telefónica y Orange \\
Telecommunications services & AT\&T, Verizon, China Mobile, Nippon Telegraph, Deutsche Telekom, Softbank Group, Vodafone, \\
& Telefónica y Orange \\
\hline
\end{tabular}

The companies with more relevance in the automotive sector have to establish their own factories, thus, increasing their size and thus quickly become global companies thus giving greater stability and profitability. One of the strategies used by automated companies in the industrial sector is the creation of divisions of digital applications, thus, generating a rapid transition to manufacturing systems such as file management, intelligent devices and other manufacturing execution systems, giving way to the management of production.

The automotive sector in Colombia is in constant threat, given that its competitiveness is affected by the high costs in production and import of inputs, as well as factors such as the tariff reduction by free trade agreements, the increase in the exchange rate and above all, due to the logistical conditions of infrastructure and transportation which do not help to have added value in the assembly of vehicles.

Advanced service sector: Differentiating the tools between manufacturing and advanced services has become more difficult in the field of advanced manufacturing. However, a benefit is generated in terms of economies, it can be recognized that the so-called 'economy of scale' which refers to entrepreneurial power when it reaches its optimal level of production, (elaborating more and reducing cost) and the 'economy of scope or scope' just as the economy of scale seeks to reduce costs, given that, together, they establish greater value by grouping the variety of products and services such as optimizing resources, to offer integrated solutions. This development is determined through the interface between the components of hardware, software and communication networks that fulfill the duty of coordinating the operation of complex processes; on the other hand, there is the dimension of 'new business models' which provide for the exercise of profitable machinery, equipment and capital-intensive infrastructure such as machinery as services, software systematization as a service or infrastructure as a service.

The importance of the software industry in advanced services and ICT, in general its contribution is in the digitization of manufacturing. The software industry is subject to economies of scale, this generates increases in productivity, becoming an engine of economic growth in the country.

Communication networks, hardware equipment and services have become the core of the industrial internet and advanced manufacturing. Next, the main software and telecommunications services companies are presented, Table 5.

One of the biggest impacts in the software industry has been the creation of companies through platforms such as Apple, Microsoft and Amazon which generated changes not only in digital services but also in the identification of advanced service activities. From ICT services which meet the same research and development criteria in the manufacturing sector advanced. These companies have contributed to improve productivity in multiple ways, these new business models have the ability to dominate the market.

In effect, this is what we want to achieve with the technology industry, transforming the factory into digital components, manufacturing processes that can be developed by computer systems fused with computational 


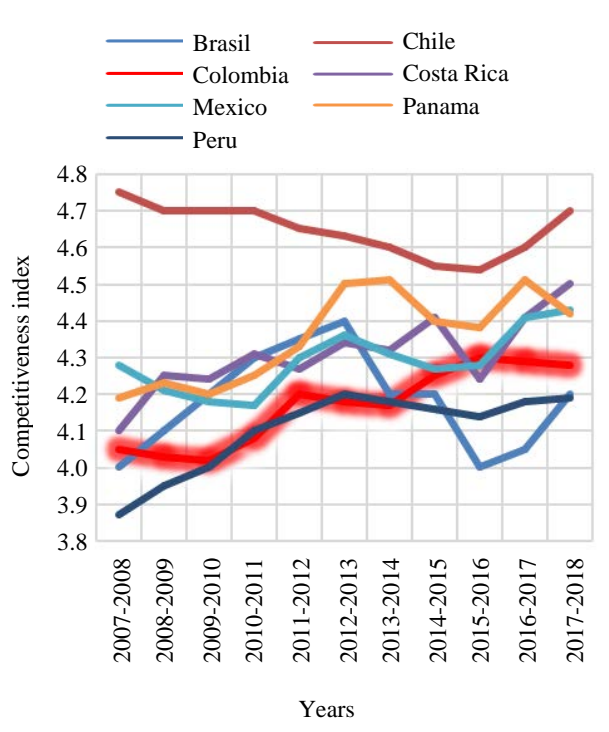

Fig. 1: Marginal advance in the global competitive index (Evolution of the IGC in the main Latin American countries)

technology to the machines themselves. For the procedure of this, it is important to mention that there are adjustable stages of insertion for automation in manufacturing processes which are:

- First stage: automation of the manufacturing process cycle

- Second stage: automation of machine systems

- Third stage: automation of the plant-company as a whole

What does need to be improved in order for the Colombian industry to be more competitive?

Opportunities for improvement for organizations are based on the reinforcement of human talent, productivity costs, the legal and regulatory system and optimization of supplier networks, through the competitiveness analysis conducted it is important to highlight that it is necessary to look for tools and innovative strategies adding the implementation of synergies with start-ups and research development centers (Moreno et al., 2017).

It is pertinent to point out that from the investment generated by the organizations to the updating of the manufacturing industry, as the Fig. 1 indicates, the positioning within the different levels of competition is reflected. For implementing new technologies such as: big data and internet of things generate as a result more attractive, functional and intelligent product for its customers (Lee et al., 2014). Four factors have a significant impact on our country's competitiveness, as reflected in Fig. 2.

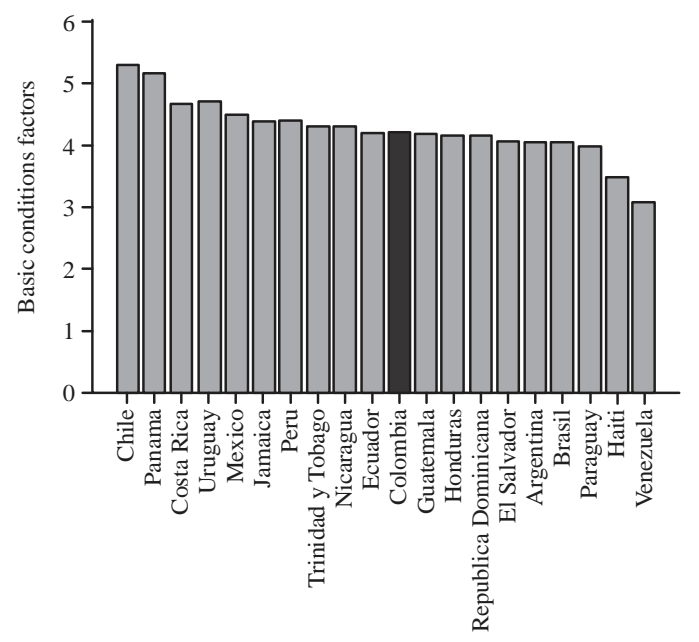

Fig. 2: Sub index of global competitiveness basic condition index, 2017-2018 (General view)

The state and its functions: The efficient public sectors in Colombia usually work to meet the objectives proposed by the state based on the following steps: minimum execution of the market distortion and low rate of tax burden applied to taxpayers; taking into account the minimum rate of public employees and the lower retention obtained from economic resources by the public mechanism. The correct line to carry out the above objectives and reach the result of these, should be transparent, corruption should not have any influence on institutions and public leaders, if so, the resources offered by the public sector should comply with maximize social profitability, in addition, the quality of the public sector is essential to achieve the objective of equity which is one of the essential purposes for the state. If this is the case, the high-quality public sector would ensure the equity of minimum costs in terms of efficiency (Busom and Velez-Ospina, 2017).

Basic education quality: Through different educational approaches, the need to increase academic levels and their quality has been discussed, given that education is essential to meet different social objectives. Education manages to combat major social problems such as: reducing poverty levels, spreading higher levels of labor growth together with wage increases, reduction of fertility rates, health and innovation of the rate in various collective sectors. It is pertinent to mention that the quality of education gives way to pluralist participation in society and strengthens access to public goods (Melguizo et al.., 2016).

Adverse Foreign trade regulatory and tax conditions: Foreign trade is developed to facilitate growth with a 
reduction in structural heterogeneity and an increase in equity. For this, the previous analyzes start from: the different trade links, productivity, growth, poverty, equity, and the transmission channels in the different levels of public policy. It is for this reason that inclusive Foreign trade is related to academic instances, policies and national and international multilateral organizations. Likewise, it can be deduced that the increase of the international trade can increase the growth, as long as it is prevented to the political adjustments oriented to achieve the objective and generates a close relationship between the different levels of the macro and microeconomics policies, not leaving aside the development of infrastructure and gender equality policies (Sinisterra et al., 2017).

The insufficient and inefficient use of human talent: Organizations that invest in the training of human talent, gain a competitive advantage through the use of resources and recreational activities, training and efficient management is executed for the right human talent, given that, this is considered a key piece to achieve the objectives of the organization, carrying out a direct relationship between the organization and its collaborators, pointing out that this talent must generate personal value, be committed and motivated (Molano et al., 2018).

\section{CONCLUSION}

The evolution of digital technologies has generated a transition from the internet of consumption to advanced manufacturing where applications have become an indispensable part of the systems individuals with multiple sensors interconnected. This is a consequence of the evolution of the internet of things with the new connectivity networks, the cloud robotics and artificial intelligence systems. Advanced manufacturing represents the new era of innovation that will revolutionize the production models of the entire economy.

The manufacturing industry in Colombia needs to establish a central axis for the fulfillment of its objectives, identifying parameters that benefit the use of emerging technology ecosystems, given that there are still low levels of investment and development in the country's companies, importance of machinery and equipment as the main source of innovation. It is observed that both the propensity to innovate and the innovative effort increase with the size of the company suggesting advantages of large companies in access to financing resources and economies of scale in production.
It was observed that this new industry format based on the automation of processes to create the so-called "connected company" will substantially increase the level of technological complexity. And to get the processes and their complexities delineated, adequate tools and software programs will be necessary to project and build functional systems and an infrastructure capable of covering these new demands.

Given this, it is valuable to promote industrial activity by innovating in the manufacturing sector which will generate significant advantages for strengthening with respect to other sectors. It is also important to strengthen the infrastructure network, so that, this allows greater added value, improves competitiveness and ensures a positioning in the Foreign market. Of course, it is necessary to recognize the ability to automate the manufacturing sector to generate productive synergies for the benefits of the economy as a whole, given that advanced manufacturing offers us an opportunity for sustainable growth through a more efficient production system. For the companies, the economic benefits will be associated in terms of productivity and efficiency for that they must overcome those infrastructure, technology and financing barriers for the incorporation of said mechanisms.

\section{RECOMMENDATIONS}

It was identified that the main technological and productive purpose within the automation in the implementation to the companies is to carry out the configuration of technological systems which allows to reach a high index in the productivity and quality of the product, obtaining a high percentage of efficiency and high technological transformation. The global capacity of the manufacturing industry has been boosted as a result of: investment and international trade of low dynamism, the braking of China's value chains and the effect of advanced economies. The technological advances associated with production, the development of cloud services, automation, robotics and artificial intelligence (Wollschlaeger et al., 2017).

One of the failures of the industrial sector in Colombia is the lack of research provided by the state and by the same companies in the field, the high devaluation of the peso made the industry less competitive, also, the signing of Free Trade Agreements (FTA) and an economic policy in general against the industry; this is how manufacturing must be transformed to be strategic, contributing to making a source of technological innovation essential for innovation in the industrial sector, helping to reduce the deficit caused by productivity and quality. 
In addition, two main ideas stand out to change the methodology of industrial companies: the need for the digital industry which seeks to promote a new innovation cycle corresponding to industrial internet. And the following is: the need to have the institutional capacities for the public sector to lead and manage transformation initiatives for advanced manufacturing and to encourage technological investment as well as to rescue the access and availability of technological suppliers and the formation of resources specialized humans. In this context, industry 4.0 has developed a route to convert the country into a leading provider of technological solutions. These strategies are part of the industrial policy approach to generate and strengthen industrial capacities through innovation in those technologies relevant to the country (mechanical engineering and construction of plants, materials technology, bio and nanotechnology, energy and environment, mobility and logistics, health and medical technology and information technologies) (Henneke et al., 2016).

Automation in the manufacturing sector represents a great wave of innovation that mandatorily generates the transformation of levels, processes and production models in order to contribute to sustainable growth by adopting productive and efficient technologies, this evolution in the industrial sector is derived from cause of the technological revolution that develops from economic globalization.

\section{REFERENCES}

Baena, F., A. Guarin, J. Mora, J. Sauza and S. Retat, 2017. Learning factory: The path to industry 4.0. Procedia Manuf., 9: 73-80.

Busom, I. and J.A. Velez-Ospina, 2017. Innovation, public support, and productivity in Colombia: A cross-industry comparison. World Dev., 99: 75-94.

Henneke, D., L. Wisniewski and J. Jasperneite, 2016. Analysis of realizing a future industrial network by means of Software-Defined Networking (SDN). Proceedings of the 2016 IEEE World Conference on Factory Communication Systems (WFCS'16), May 3-6, 2016, IEEE, Aveiro, Portugal, pp: 1-4.

IEC., 2015. Factory of the future. International Electrotechnical Commission, Geneva, Switzerland.

Kolberg, D. and D. Zuhlke, 2015. Lean automation enabled by industry 4.0 technologies. IFAC. Pap. OnLine, 48: 1870-1875.

Lee, J., H.A. Kao and S. Yang, 2014.. Service innovation and smart analytics for industry 4.0 and big data environment. Procedia CIRP., 16: 3-8.
Melguizo, T., F. Sanchez and T. Velasco, 2016. Credit for low-income students and access to and academic performance in higher education in Colombia: A regression discontinuity approach. World Dev., 80: 61-77.

Molano, J.I.R., S.J.G. Moncada and K.D.L. Parra, 2018. Impact of implementing industry 4.0 in Colombia'ssupply chains. Proceedings of the International Conference on Data Mining and Big Data (DMBD'18), June 17-22, 2018, Springer, Berlin, Germany, pp: 704-713.

Moreno, J., M. Galeano and H. Montiel, 2017. Recommendations for the production lines of the future factory in Colombia. Intl. J. Appl. Eng. Res., 1: $14820-14825$.

Morrish, J., K. Figueredo, S. Haldeman and V. Brandt, 2016. The industrial internet of things, Volume B01: Business strategy and innovation framework. Industrial Internet Consortium, Needham, Massachusetts, USA.

Panfilenko, D., P. Poller, D. Sonntag, S. Zillner and M. Schneider, 2016. BPMN for knowledge acquisition and anomaly handling in CPS for smart factories. Proceedings of the 2016 IEEE 21st International Conference on Emerging Technologies and Factory Automation (ETFA 16), September 6-9, 2016, IEEE, Berlin, Germany, pp: 1-4.

Qin, J., Y. Liu and R. Grosvenor, 2016. A categorical framework of manufacturing for industry 4.0 and beyond. Procedia CIRP., 52: 173-178.

Rubmann, M., M. Lorenz, P. Gerbert, M. Waldner and J. Justus et al., 2015. Industry 4.0: The future of productivity and growth in manufacturing industries. Boston Consulting Group, 9: $1-14$.

Sinisterra, K.V.B., S.M. Mejia and J.I.R. Molano, 2017. Industry 4.0 and its development in Colombian industry. Proceedings of the International Workshop on Engineering Applications (WEA 17), September 27-29, 2017, Springer, Berlin, Germany, pp: 312-323.

Smit, J., S. Kreutzer, C. Moeller and M. Carlberg, 2016. Industry 4.0, directorate general for internal policies. European Parlament, Brussels, Belgium.

Thoben, K.D., S. Wiesner and T. Wuest, 2017. Industrie 4.0 and smart manufacturing-A review of research issues and application examples. Int. J. Autom. Technol., 11: 4-16. 
Trappey, A.J.C., C.V. Trappey, U.H. Govindarajan, J.J. Sun and A.C. Chuang, 2016. A review of technology standards and patent portfolios for enabling cyber-physical systems in advanced manufacturing. IEEE. Access, 4: 7356-7382.

Wollschlaeger, M., T. Sauter and J. Jasperneite, 2017. The future of industrial communication: Automation networks in the era of the internet of things and industry 4.0. IEEE. Ind. Electron. Mag., 11: 17-27.
Zimmermann, M., F.W. Baumann, M. Falkenthal, F. Leymann and U. Odefey, 2017. Automating the provisioning and integration of analytics tools with data resources in industrial environments using OpenTOSCA. Proceedings of the 2017 IEEE 21stInternational Enterprise Distributed Object Computing Workshop (EDOCW 17), October 10-13, 2017, IEEE, Quebec, Canada, pp: 3-7. 